\title{
A Revised Key to the Living and Fossil Families of Strepsiptera, with the Description of a New Family, Cretostylopidae
}

\author{
Jeyaraney Kathirithamby $^{1}$ and Michael S. Engel ${ }^{2,3}$

\begin{abstract}
A new family, Cretostylopidae Kathirithamby and Engel, is erected to
KEY WORDS: Strepsiptera, twisted-winged parasites, Cretostylops, fossil, identification key
\end{abstract} \\ accommodate the mid-Cretaceous species Cretostylops engeli Grimaldi and Kathirithamby. \\ Based on this as well as various other recent works pertaining to the higher classification of \\ Strepsiptera, a revised key is provide to the living and fossil families.
}

Recently there has been increased interest in the higher classification of evolution of the twisted-winged parasites (Strepsiptera). Indeed, many new changes have been proposed by a variety of authors, particularly in regard to some new fossil and primitive modern lineages (e.g., Grimaldi et al., 2005; Pohl and Beutel, 2005; Pohl et al., 2005; Bravo et al., 2009). Despite this fervor of activity, there has been no revised means through which to identify this diversity. Accordingly, we provide a revised key to the living and fossil families of Strepsiptera. The key is provided here to permit identification not only of recently proposed families (Pohl and Beutel, 2005; Pohl et al., 2005; Bravo et al., 2009), but also a family newly established herein. It has been long known that the Cretaceous genus Cretostylops Grimaldi and Kathirithamby is representative of a distinct group of extinct strepsipterans (e.g., Grimaldi et al., 2005; Bravo et al., 2009), but the group has never been formally established under the ICZN. Thus, we herein establish the family and incorporate this group into the newly expanded key. The family includes only the species Cretostylops engeli Grimaldi and Kathirithamby, from the mid-Cretaceous deposits of northern Myanmar (Grimaldi et al., 2005).

A few additional changes are incorporated herein. Protoelencholacidae was erected by Pohl \& Beutel (2005) to include the fossil Protoelencholax schleei Kinzelbach (1979), but the differences given - slender mandibles with mediallycrossing, blade-like apices and two tarsomeres - are typical characters of Elenchidae and do not sufficiently distinguish the group. We therefore retain this species within Elenchidae. Also, based on the results of a recent molecular analysis, Callipharixenidae was placed in the Halictophagidae and Lychnocolacidae was recognized as a family distinct from the Myrmecolacidae (McMahon et al., 2011). These alterations of the higher classification are also incorporated herein.

Throughout, groups known only as fossils are denoted with a dagger $(\dagger)$ and other families that are also recorded from the fossil record are mentioned as such. The current classification of the order is summarized in Table 1.

\footnotetext{
${ }^{1}$ Department of Zoology, Oxford University, South Parks Road, Oxford OX1 3PS, United Kingdom (jeyaraney.kathirithamby@zoo.ox.ac.uk).

${ }^{2}$ Division of Entomology, Natural History Museum, and Department of Ecology \& Evolutionary Biology, 1501 Crestline Drive - Suite 140, University of Kansas, Lawrence, Kansas 66045 (msengel@, ku.edu).

${ }^{3}$ Division of Invertebrate Zoology, American Museum of Natural History, Central Park West at $79^{\text {th }}$ Street, New York, New York 10024-5192 (mengel@amnh.org).
} 
Table 1. Hierarchical classification of Strepsiptera.

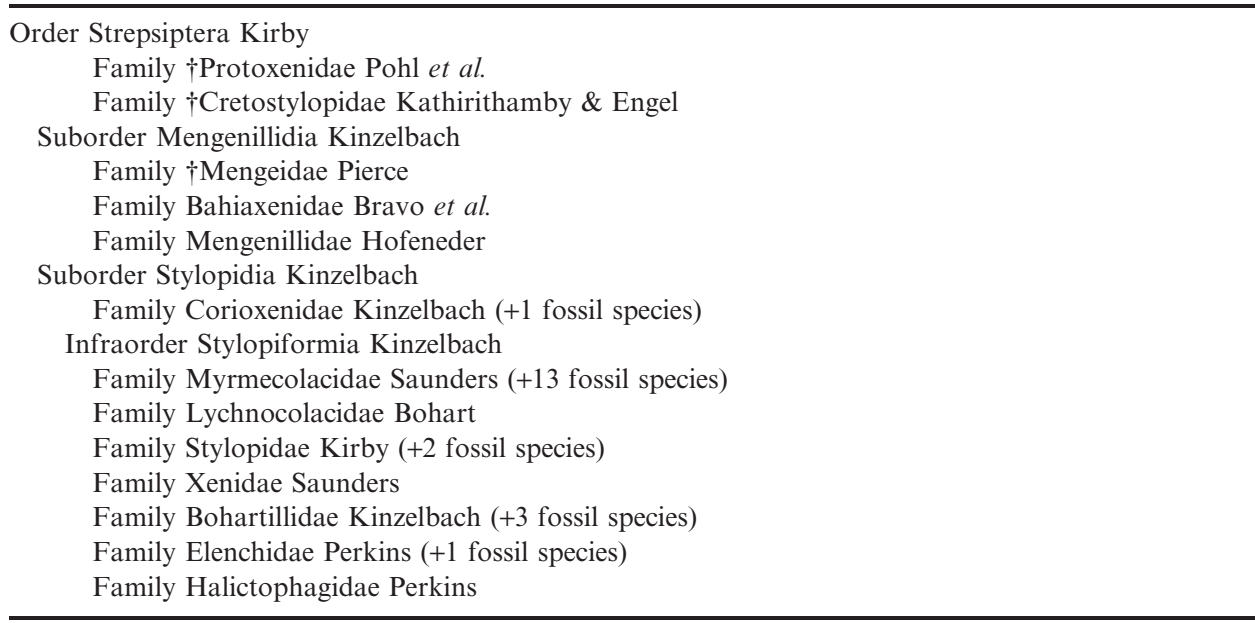

Key to Families of Strepsiptera

(Adult males, living \& fossil)

1. Tarsi 5 segmented, pretarsus with pair of strong claws . . . . . . . . 2

-. Tarsi 2-5 segmented; pretarsus with neither claws nor sensory spots; or tarsi 5-segmented and pretarsus with a pair of very weak claws, or a single claw and with sensory spots .............. 6

2(1). Antenna 8 segmented; mandibles large and robust, triangular shaped, with broad base and of generalized chewing structure. . . . . . . . 3

-. Antenna 6-7 segmented; mandibles, if present, small, narrow, and blade-

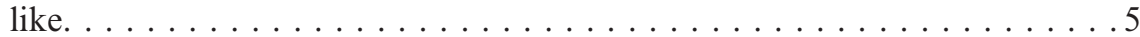

3(2). Galeal lobe at base of maxillary palp present. . . . . . . . † Protoxenidae

- Galeal lobe at base of maxillary palp absent . . . . . . . . . . . . . .4

4(3). Protrochanter and profemur free ........ . Cretostylopidae, n. fam.

-. Protrochanter and profemur fused (Host: unknown). . . . . . Bahiaxenidae

5(2). Prementum free, with short palps; hind wing $\mathrm{CuA}_{1}$ short, extending about to middle of wing; front branch of MA absent; antenna 7segmented, with flabella on antennomeres III and IV . . . . † Mengeidae

-. Prementum fused to hypopharynx; hind wing $\mathrm{CuA}_{1}$ extending almost to edge of wing; MA strongly developed with anterior branch; antenna 6segmented, with flabella on antennomeres III to IV or III to V (Host: Zygentoma: Lepismatidae) . . . . . . . . . . . . . Mengenillidae

6(1). Mandibles absent; tarsi 4-5 segmented, pretarsus with a pair of claws, or a single claw, or tarsi 4 segmented and pretarsus without claws; antenna 5-7 segmented, with flabella on antennomeres III-IV or III-V (Host: Hemiptera: Cydnidae, Blissidae, Pentatomidae, Lygaeidae, Coreidae) (also known from fossils) . . . . . . . . . . . . . . Corioxenidae

-. Mandibles present, narrow and blade-like; tarsi 2-4 segmented, pretarsus without claws; antenna 4-7 segmented, with flabella on antennomeres only on III or IV, or III \& IV, or III to V, or III, V, \& VI,

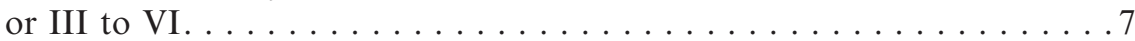


7(6). Tarsi 3 segmented (Host: Hemiptera: Cercopidae, Cicadellidae, Coreidae, Delphacidae, Eurybrachyidae, Flatidae, Fulgoridae, Issidae, Membracidae, Pentatomidae, Tettigometridae; Diptera: Tephritidae; Orthoptera: Tridactylidae; Blattaria: Blattellidae) . . . . . . Halictophagidae

— Tarsi 2 or 4 segmented. . . . . . . . . . . . . . . . . . .8

8(7). Tarsi 2 segmented; antenna 4 segmented (Host: Hemiptera: Delphacidae, Dictyopharidae Eurybrachidae, Flatidae, Fulgoridae, Ricaniidae). . .Elenchidae

—. Tarsi 4 segmented; antenna 5-7 segmented . . . . . . . . . . . . . 9

9(8). Antennae 7 segmented, with flabella on antennomeres III, V, and VI; maxillary base five times longer than palpus (Host: unknown) (also known from fossils) . . . . . . . . . . . . . . . Bohartillidae

- Antennae 4-7 segmented, with flabellum on antennomere IIII only; maxillary base equal to, or smaller than palpus . . . . . . . . 10

10(9). Antenna 4 or 6 segmented, with flattened flabella . . . . . . . . . . 11

- Antenna 7 segmented, with rounded flabella . . . . . . . . . . . . 12

11(10). Antenna 6 segmented, metathorax with spoon-shaped sclerite (Host: Hymenoptera: Andrenidae, Colletidae, Halictidae) (also known from fossils) . . . . . . . . . . . . . . . . . . Stylopidae

-. Antenna 4 segmented, metathorax with no spoon-shaped sclerite (Host: Hymenoptera: Masaridae, Mutillidae, Sphecidae, Vespidae) . . . . . Xenidae 12(10). Wing venation with $\mathrm{CuA}_{1}$ and $\mathrm{CuA}_{2}$ present (Host: unknown) . . . . . . $\ldots \ldots \ldots \ldots \ldots$. . . . . . . . . . . . . . . . . . . . . . . .

-. Wing venation with only $\mathrm{CuA}_{1}$ (Host: Males - Hymenoptera: Formicidae: Dolichoderinae, Ecitoninae, Formicinae, Myrmicinae, Pseudomyrmecinae, Ponerinae / Females - Orthoptera, Mantodea) (also

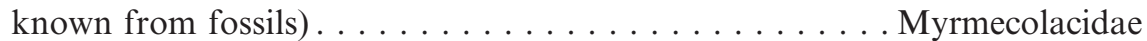

\section{Systematic Paleontology}

Cretostylopidae Kathirithamby \& Engel, new family

TYPE GENUS: Cretostylops Grimaldi and Kathirithamby in Grimaldi et al. (2005). DESCRIPTION: Male. Body size small (ca. $1.5 \mathrm{~mm}$, much smaller than the massive Protoxenos Pohl et al. which is ca. $7 \mathrm{~mm}$ ); antenna 8-segmented, with 6 flabella on antennomeres III-VIII (a plesiomorphic condition for Strepsiptera, similar to that of Protoxenos); bases of antennae situated between compound eyes; ommatidia small, not separated by microtrichia; mandibles robust, sclerotized, large, and triangular (a distinctive plesiomorphy shared with Protoxenos, and unlike the mandibles in Bahiaxenos which are large but not as robust as other Recent Strepsiptera in which they are narrow, small, and blade-like); maxillary lobe lacking galeal lobe (as in all other Strepsiptera except Protoxenos); labrum reduced (also present in Protoxenos but absent in all other strepsipterans except Mengea Grote and the Australian Mengenilla Hofeneder); tarsi long and pentamerous; pretarsus with a pair of claws, setae absent (present in Protoxenos and all basal extant groups such as Bahiaxenidae and Mengenillidae); pseudohalters (forewings) large; hind wings with well-developed $\mathrm{R}_{1}$ and $\mathrm{R}_{4}$, with pterostigma-like thickening; protrochanter and profemur free (unlike all extant Strepsiptera).

Female. Unknown. 
COMmEnTs: The earliest known Strepsiptera and the first described from the Mesozoic is C. engeli (Grimaldi et al., 2005; Grimaldi and Engel, 2005), preserved in mid-Cretaceous amber from Myanmar. All phylogenetic analyses which included both fossil and modern families recover the extinct genus Protoxenos, in middle Eocene Baltic amber, as sister to all other Strepsiptera, with Cretostylops the next lineage to diverge (Grimaldi et al., 2005; Pohl and Beutel, 2005; Bravo et al., 2009; Hünefield et al., 2011). Although Cretostylops is older (99 Ma) than Protoxenos (45 Ma), the latter is clearly supported as the most basal group and must have been an ancient relic lineage even by the Paleogene.

\section{Acknowledgements}

We are grateful for the input from two anonymous reviewers and Roy J. Beckemeyer. This is a contribution of the Division of Entomology, University of Kansas Natural History Museum.

\section{Literature Cited}

Bravo, F., H. Pohl, A. Silva-Neto, and R. G. Beutel. 2009. Bahiaxenidae, a "living fossil" and a new family of Strepsiptera (Hexapoda) discovered in Brazil. Cladistics 25(6):614-623.

Grimaldi, D., and M. S. Engel. 2005. Evolution of the Insects. Cambridge University Press, Cambridge, UK. xv+755 pp.

Grimaldi, D., J. Kathirithamby, and V. Schawaroch. 2005. Strepsiptera and triungula in Cretaceous amber. Insect Systematics and Evolution 36(1):1-20.

Hünefield, F., H. Pohl, B. Wipfler, F. Beckmann, and R. G. Beutel. 2011. The male postabdomen and genital apparatus of Mengea tertiaria, a strepsipteran amber fossil (Insecta). Journal of Zoological Systematics and Evolutionary Research 49(4):298-308.

Kinzelbach, R. K. 1979. Das erste neotropische Fossil der Fächerflügler (Stuttgarter Bernsteinsammlung: Insecta, Strepsiptera). Stuttgarter Beiträge zur Naturkunde, Serie B (Geologie und Paläontologie) 53:1-14.

McMahon, D. P., A. Hayward, and J. Kathirithamby. 2011. The first molecular phylogeny of Strepsiptera (Insecta) reveals an early burst of molecular evolution correlated with the transition to endoparasitism. PLoS ONE 6:e21206 [1-10].

Pohl, H., and R. G. Beutel. 2005. The phylogeny of Strepsiptera (Hexapoda). Cladistics 21(4):328-374.

Pohl, H., R. G. Beutel, and R. Kinzelbach. 2005. Protoxenidae fam. nov. (Insecta, Strepsiptera) from Baltic amber - a 'missing link' in strepsipteran phylogeny. Zoologica Scripta 34(1):57-69. 